\title{
LA ADMISIBILIDAD DEL RECURSO DE INAPLICABILIDAD: A TRES AÑOS DE LA REFORMA*
}

\author{
Nicolás Massmann Bozzolo**
}

\begin{abstract}
RESUMEN
La ley 20.050 de reforma constitucional condicionó la admisibilidad del recurso de inaplicabilidad al cumplimiento de los requisitos del artículo 93 inciso 11 de la Carta Fundamental. La jurisprudencia de inadmisibilidades, a lo largo de estos años, ha sido abundante y permite extraer determinados criterios que han orientado el razonamiento del Tribunal en este punto. El presente es un estudio sobre los principales criterios que es posible identificar en dicha jurisprudencia.
\end{abstract}

\begin{abstract}
The constitutional reform act 20,050 conditioned the admissibility of the action of inapplicability to the fulfillment of the requirements of Article 93, paragraph 11 of the Constitution. The jurisprudence of inadmissibility, throughout these years, has been plentiful and allows extract certain criteria that have guided the Court's reasoning on this point. This is a study on the main criteria to be identified in that jurisprudence.
\end{abstract}

PALABRAS CLAVES

Ley 20.050; Tribunal Constitucional; Recurso de inaplicabilidad; Admisibilidad.

\section{KEY WORDS}

Law 20.050; Constitutional Court; Action of inapplicability; Admissibility.

\footnotetext{
* Trabajo recibido con fecha 16 de octubre de 2008, y aprobada su publicación con fecha 20 de marzo de 2009.

** Licenciado en Ciencias Jurídicas y Sociales de la Universidad de los Andes, Abogado. Profesor de Instituciones del Derecho Positivo, Universidad de los Andes. Correo electrónico: nmassmann@uandes.cl.
} 


\section{Introducción}

La reforma constitucional de 2005 modificó la composición del Tribunal Constitucional y fortaleció sus atribuciones en el control de constitucionalidad de las leyes. Con razón algunos autores han comentado que desde entonces podemos hablar de un "nuevo" Tribunal inspirado en un concepto fuerte de justicia constitucional ${ }^{1}$, habilitado para revisar la constitucionalidad de prácticamente todas las normas jurídicas de nuestro ordenamiento.

La doctrina, por otra parte, es relativamente unánime en reconocer que el traspaso del recurso de inaplicabilidad, desde la Corte Suprema al Tribunal Constitucional, junto con la acción de inconstitucionalidad para invalidar un precepto declarado inaplicable, son las atribuciones más trascendentes que la reforma confió a la magistratura constitucional ${ }^{2}$.

En cuanto a la inaplicabilidad, la reforma también constitucionalizó los requisitos de admisibilidad del recurso, al consagrarlos expresamente en el texto constitucional. En otras palabras, dejó fuera del alcance del legislador los criterios fundamentales que el Tribunal deberá considerar al determinar el curso de los requerimientos presentados ${ }^{3}$.

Transcurridos prácticamente tres años desde que el Tribunal se pronunciara sobre la primera inaplicabilidad, es posible identificar algunos criterios que han guiado su deliberación en las declaraciones de inadmisibilidad. Muchos de ellos ya se encontraban en la respectiva jurisprudencia de nuestra Corte Suprema. Sin embargo, van siendo numerosos y, en ciertos casos, de extrema relevancia, los nuevos criterios aparecido a partir de 2006. El Tribunal ha delineado, a través de la jurisprudencia de admisibilidad, los perfiles que configuran la nueva acción de inaplicabilidad.

Los requisitos que se exigen para que el Tribunal conozca del fondo del requerimiento se encuentran en el artículo 93 inciso 11 de la Constitución. Allí se señala que corresponderá a cualquiera de las salas declarar la admisibilidad del recurso siempre que verifique la existencia de una gestión pendiente ante el tribunal ordinario o especial, que la aplicación del precepto legal impugnado pueda resultar decisivo en la resolución de un asunto, que la impugnación esté fundada razonablemente y se cumplan los demás requisitos que establezca la ley.

\footnotetext{
$1 \quad C f r$. Cea, José Luis, "Rol del nuevo Tribunal constitucional en la democracia chilena", en Escritos de Justicia Constitucional, Santiago, Cuadernos del Tribunal Constitucional, No 35, 2007, pp. 93-101; Hernán Hormazábal, El nuevo Tribunal Constitucional, Santiago, Lexis Nexis, 2006.

2 Emplearemos los conceptos acción y recurso indistintamente. El Tribunal también ha omitido la distinción en algunas sentencias (v.gr. rol 546-06 parte II: "Por acoger el recurso"). Coincidimos, sin embargo, con la doctrina procesal que entiende que se trata de una acción, pues no impugna resoluciones judiciales.

3 Pensamos que la Ley Orgánica, actualmente en trámite de reforma, no podrá restringir los requisitos de admisibilidad sino únicamente añadir otros. Aún así, los nuevos requisitos no podrán dejar inoperantes a los consagrados en la misma Constitución.
} 
La admisibilidad del recurso de inaplicabilidad: a tres años de la reforma.

Por tanto, el requerimiento deberá contener, antes que todo, los siguientes elementos:

1. Demostrar la existencia de una gestión que se encuentre pendiente a la fecha de la presentación del recurso, ante un tribunal ordinario o especial.

2. Que la norma impugnada sea un precepto de naturaleza o rango legal.

3. El precepto cuya aplicación se impugna pueda resultar decisivo para la resolución de un asunto.

4. El requerimiento debe encontrarse razonablemente fundado.

5. Cumplir los demás requisitos que determine la ley, los que actualmente están establecidos en la Ley Orgánica del Tribunal Constitucional (17.997).

\section{Inaplicabilidad y control concreto de constitucionalidad}

Tradicionalmente, la Corte Suprema y la doctrina interpretaron la inaplicabilidad como una acción de control abstracto de constitucionalidad de la ley. Que sea un control abstracto significa, en palabras de la Corte, que el mandato, prohibición o permiso contenido en la norma cuestionada, contrasta en general con aquellos que se consagran en la Constitución, de manera que el precepto constitucional resulta incompatible con la norma impugnada "en sí”, y no solo en la forma específica en que esta última pretende aplicarse en el caso concreto de que se trata. ${ }^{4}$

La inaplicabilidad fue interpretada, entonces, como un recurso de control abstracto, sin perjuicio de que la Constitución exigiera la concurrencia de una gestión pendiente donde se advirtiera la inconstitucionalidad de aplicar el precepto. No era la aplicación de la ley aquello que se sometía a control, sino la norma, abstractamente considerada, aquello que se confrontaba con el texto constitucional al margen de los hechos y circunstancias subyacentes al conflicto ${ }^{5}$.

4 Gaceta Jurídica, № 218, agosto 98, p. 83, fallo “Fuenzalida Navarrete, Gastón”, cons. 2º, en Ríos, Lautaro, “La acción de inaplicabilidad de preceptos legales", en Revista de Derecho, Universidad Católica del Norte, 2007, año $14, \mathrm{~N}^{\circ} 2$, p. 125.

5 Alguna doctrina, comentando la primera jurisprudencia del Tribunal, consideró que el carácter abstracto de la inaplicabilidad se mantuvo inalterado. Cfr. Saenger, Fernando, "Acción de inaplicabilidad y acción de inconstitucionalidad. Facultades del nuevo Tribunal Constitucional", en Revista de Derecho de la Universidad Católica de la Santísima Concepción, № 14, 2006, p. 39: La labor antes de la Corte Suprema y hoy del Tribunal Constitucional es meramente abstracta y de comparación entre lo que dice la Carta como norma Suprema y los textos productos [sic] de la función legislativa. 
El Tribunal, desde sus primeras sentencias de inaplicabilidad, ha mostrado que esta interpretación ya no es posible. Los términos en que se encuentra consagrado el recurso después de la reforma no lo permiten ${ }^{6}$. La competencia del Tribunal es para resolver "la inaplicabilidad de un precepto legal cuya aplicación (...) resulte contraria a la Constitución" (93 n. 6) y no, como hasta antes de la reforma, la inaplicabilidad de "todo precepto legal contrario a la Constitución" (art. 80, reformado). Como bien apunta Martínez, "probablemente se incluyó está expresión con el fin de enfatizar el carácter concreto de esta forma de control, que contrasta con la competencia natural del Tribunal Constitucional para ejercer control abstracto de constitucionalidad"7.

En consecuencia, desde su jurisprudencia más temprana se puede observar la relevancia que el Tribunal concede a los hechos y circunstancias de las controversias que debe resolver. En otros términos, la nueva inaplicabilidad pone en marcha un proceso jurisdiccional donde la tarea del Tribunal consiste en subsumir los hechos del caso a las normas constitucionales para extraer de allí la solución del conflicto, y no un enjuiciamiento sobre la validez de la norma legal que abstractamente se confronta con la Carta Fundamental ${ }^{8}$.

La fórmula utilizada por el Tribunal para explicar este nuevo enfoque ha sido la siguiente: En sede de inaplicabilidad, el Tribunal está llamado a determinar si la aplicación del precepto en la gestión específica resulta contraria a la Constitución ${ }^{9}$. Nótese que lo contrario -a juicio del Tribunal- no es el precepto, sino su aplicación -“contraria a la Constitución"-, y si se quiere, (cfr. infra III. 3) la eventual aplicación o interpretación ${ }^{10}$, pues no será necesario esperar

Con todo, su temprana jurisprudencia permaneció fiel al antiguo modo de interpretar la inaplicabilidad, como se desprende del cons. 24 de una sentencia interlocutoria, que resolvió un incidente de incompetencia del Tribunal, en rol 472: Desde este punto de vista, es necesario consignar que si bien la acción de inaplicabilidad de las leyes es de derecho estricto que tiende a confrontar dos normas jurídicas, una legal y otra constitucional, como lo ha reiterado la jurisprudencia uniforme de los tribunales de justicia, no es menos cierto que detrás de la aplicación de un precepto legal inconstitucional en un caso concreto se encuentra la vulneración de un derecho fundamental, lo que no puede dejar indiferente a esta Magistratura Constitucional (...) [El destacado en nuestro]. El Tribunal permanecía ligado a la interpretación de la Corte Suprema en este punto, sin perjuicio de añadir consideraciones anexas que lo "obligaban" a revisar la aplicación del precepto "inconstitucional", para salvaguardar la supremacía constitucional en juego. También en la línea del control abstracto y siendo jurisprudencia más reciente que la citada, rol 733-07 cons. $5^{\circ}$ : si bien la acción deducida está dentro de la competencia de este Tribunal para analizar normas legales como las impugnadas en la especie para después confrontarlas con la normativa constitucional vigente y emitir la resolución de rigor (...).

7 Martínez, José Ignacio, "Recurso de inaplicabilidad, Tribunal Constitucional y juez ordinario en la reforma constitucional", en La Constitución reformada de 2005, Santiago, Librotecnia, 2005, p. 461.

8 Esto es lo que critica Fernando Atria al modo "canónico" de entender el recurso, cuando señala que la inaplicabilidad es una "tarea propiamente jurisdiccional". Ver Atria, Fernando, "Inaplicabilidad y coherencia: contra la ideología del legalismo", en Revista de Derecho (Universidad Austral), 2001, Vol. 12, N 1, pp. 119-156.

9 Véanse también, por ejemplo, roles $480-06$ cons. $27^{\circ}$ y $806-07$ cons. $26^{\circ}$.

10 Cfr. Fermandois, Arturo, "Inaplicabilidad y control concreto del Tribunal Constitucional: enjuiciando la arbitrariedad en la aplicación de la ley”, en Actualidad Jurídica, n. 17, 2008, p. 176-177. 
La admisibilidad del recurso de inaplicabilidad: a tres años de la reforma.

la sentencia del juez de fondo- donde finalmente se apreciará la forma en que se aplicó o interpretó el precepto-, para requerir de inaplicabilidad. El recurso está ideado para impugnar la presumible interpretación o aplicación de un precepto en el contexto de un litigio, cuando se estima que será contraria a la Constitución.

El Tribunal también ha puesto de manifiesto esta nueva dimensión del recurso, explicando que el que en un caso determinado se declare un precepto legal inaplicable por inconstitucional, no significa que siempre y en cualquier caso procederá formular igual declaración ${ }^{11}$.Igualmente ha observado que las características y circunstancias del caso concreto de que se trate, han adquirido en la actualidad una relevancia mayor de la que debía atribuírseles antes de 2005 pues, ahora, la decisión jurisdiccional de esta Magistratura ha de recaer en la conformidado contrariedad con la Constitución que la aplicación del precepto impugnado pueda tener en cada caso concreto, lo que no implica, necesariamente, una contradicción abstracta y universal con la preceptiva constitucional ${ }^{12}$

Esta nueva comprensión del recurso ha sido determinante para la interpretación de los criterios de admisibilidad consagrados en la Constitución ${ }^{13}$.

\section{Los requisitos de admisibilidad a la luz de la jurisprudencia del Tribunal Constitucional}

\section{Falta de gestión pendiente}

a) Observación previa:

La acción de inaplicabilidad está diseñada para sustraer ciertos preceptos legales del alcance judicial, de modo que el juez queda obligado a omitirlos al momento de resolver un asunto sometido a su conocimiento. El Tribunal ha llamado efecto negativo al que produce una declaración de inaplicabilidad, ya que prohíbe al juez utilizar la norma impugnada para resolver el conflicto, pero al mismo tiempo no le indica cómo deberá fallar o qué preceptos legales podrá en adelante aplicar ${ }^{14}$. Todo esto presupone que los preceptos legales en cuestión no hayan sido aún aplicados y la gestión judicial en la que incidirán deberá encontrarse abierta al promoverse la inaplicabilidad: la acción de inaplicabilidad es un medio de evitar la aplicación

Rol 616-06, cons. $51^{\circ}$.

Rol 623-06, cons. $11^{\circ}$.

Algunos estudios han profundizado en la naturaleza de control concreto de la inaplicabilidad después de la reforma de 2005. Cfr. Fermandois, Arturo, cit. nota 10; Ríos, Lautaro, cit. nota 4, pp. 115- 130.; Hormazábal, Hernán, cit. nota 1, pp. 36-39.

$14 \quad C f r$ rol 473-07, cons. $9^{\circ}:(. .$.$) declarado por esta Magistratura que un precepto legal preciso es inaplicable en$ la gestión respectiva, queda prohibido al tribunal ordinario o especial que conoce de ella aplicarlo. 
de normas legales determinadas contenidas en una gestión judicial que no ha concluido (...) (Rol. 981-07, cons. $4^{\circ}$ ).

De alguna forma, el recurso de inaplicabilidad tiene una cierta naturaleza cautelar y preventiva. El requirente solicita que se le proteja de los efectos inconstitucionales que pueden derivarse de la aplicación de un precepto legal en la gestión dentro de la cual se promueve. La supremacía constitucional que resguarda es únicamente aquella que podría verse vulnerada dentro de la tramitación judicial de un asunto, por los efectos que genera la aplicación de un precepto $^{15}$. Esta naturaleza cautelar ha sido reconocida por el Tribunal. Al declarar inadmisible un requerimiento de inaplicabilidad cuya gestión pendiente consistía en un recurso de protección el Tribunal razonó señalando que resulta claro que el actor, obrando de la forma que permite el artículo 20 de la Ley Fundamental, interpuso ante la jurisdicción competente una acción cautelar de naturaleza preventiva en su favor y, también, que la gestión en la que ésta incide se encuentra pendiente de resolución. Sin embargo, debe observarse que ello no lo habilita para solicitar a esta Magistratura una declaración de inaplicabilidad por inconstitucionalidad del mismo carácter preventivo, según se desprende del numeral $6^{\circ}$ y del inciso undécimo del artículo 93 de la Constitución, antes transcritos (Rol 733-07, cons. $8^{\circ}$ ).

Desde otro punto de vista, la exigencia de una gestión pendiente responde a la naturaleza de control concreto de la acción. Al contrario de los que se podría pensar, la gestión pendiente no es una técnica para contener las solicitudes de control constitucional que podrían producirse si nada se exigiera para activar este mecanismo de control. ${ }^{16}$ La gestión pendiente, en cambio, permite al Tribunal dimensionar los efectos que la aplicación del precepto puede producir, constituyendo una parte integrante del mismo.

\section{b) Jurisprudencia del Tribunal:}

i) No hay gestión pendiente una vez que se produce cosa juzgada en la gestión.

En múltiples ocasiones el Tribunal ha declarado inadmisibles recursos que se presentan una vez agotada la etapa jurisdiccional habiéndose dictado sentencia definitiva, o bien, cuando ha alcanzado fuerza o eficacia de cosa juzgada. Por eso, consideraciones como la siguiente son habituales cuando no se cumple con este requisito de admisibilidad: la acción de inaplicabilidad instaura un proceso dirigido a examinar la constitucionalidad de un precepto legal cuya

15 La supremacía constitucional, como principio ordenador de las fuentes jurídicas, admite múltiples formas de hacerse efectiva y las competencias para esto se encuentran distribuidas entre diversos órganos legitimados. La inaplicabilidad tan sólo resguarda el principio en sede jurisdiccional, es decir, ligada a la aplicación de las normas a los hechos.

16 Para un comentario crítico sobre el modo como la Corte Suprema y alguna doctrina interpretó el recurso de inaplicabilidad, c $f r$. Atria, Fernando, cit. nota 8. 
La admisibilidad del recurso de inaplicabilidad: a tres años de la reforma.

aplicación en una gestión pendiente que se siga ante un tribunal ordinario o especial, resulte contrario a la Constitución. En consecuencia, la acción de inaplicabilidad es un medio de evitar la aplicación de normas legales determinadas contenidas en una gestión judicial que no ha concluido, en el evento que dichos preceptos puedan resultar derecho aplicable al caso sub-lite (Rol 981-07, cons. $4^{\circ}$; énfasis añadido) ${ }^{17}$

Por otra parte, tampoco existe gestión pendiente cuando la magistratura de fondo dicta sentencia de término entre la presentación del recurso y la vista de su admisibilidad. En otras palabras, cuando la gestión se encontraba efectivamente pendiente al momento de presentar el requerimiento, pero una vez que se procede a estudiar su admisibilidad, el juez de fondo ya ha dictado sentencia. En rol 764-07 la Magistratura Constitucional declaró inadmisible un requerimiento dirigido a obtener la inaplicabilidad del inciso segundo del artículo 387 del Código Procesal Penal, que impide al condenado recurrir de nulidad para dejar sin efectos el segundo juicio oral en que se dictó sentencia condenatoria ${ }^{18}$. La presentación fue hecha después de que el Tribunal Oral dictara el veredicto, pero antes de que se cumpliera con el requisito de lectura de la sentencia (4 de abril de 2007). Es decir, mientras aún existía gestión pendiente. Sin embargo, fue declarada inadmisible por falta de gestión pendiente, pues la vista de su admisibilidad fue posterior a dicho trámite (9 de abril de 2007) y así lo declaró el Tribunal: consta del certificado estampado con fecha 10 de abril del año en curso por el Secretario de este Tribunal Constitucional, que la sentencia dictada en los referidos autos criminales -RIT 273-2006-, se encuentra ejecutoriada a contar del día 9 de abril de 2007. En consecuencia, en este caso resulta evidente que no existe una gestión pendiente ante un tribunal ordinario o especial en la cual pudiera recibir aplicación el inciso segundo del artículo 387 del Código Procesal Penal, precepto que, como antes se ha indicado, es objeto del presente requerimiento (cons. $7^{\circ}$ ).

También puede suceder que al momento de estudiarse la admisibilidad exista gestión pendiente, pero deje de haberla al momento de fallar el fondo del requerimiento presentado. Fue lo que sucedió, por ejemplo, en rol 500-06. El Tribunal declaró admisible, el 11 de julio de 2006, un requerimiento presentado el 3 de mayo del mismo año. Sin embargo, al adoptarse acuerdo sobre el fondo del mismo, dicha gestión dejó de existir, pues el 18 de octubre de ese año se había dictado sentencia definitiva ${ }^{19}$. De ello dan cuenta el considerando cuarto y quinto de la sentencia de inadmisibilidad: CUARTO: Que como consta del certificado extendido por

$17 \quad C f r$. entre otros, rol 1004-07, 981-07 y 1134-08.

18 Cfr. Buchheiser, Axel y Candia, Gonzalo, "Sociedad libre y debido proceso: una relación necesaria. Comentario del fallo de inadmisibilidad 'Tocornal', en Sentencias Destacadas 2007, Libertad y Desarrollo, Santiago, p. 193-224.

19 Como se sabe, la Sala está facultada para suspender el procedimiento que motiva la inaplicabilidad. La facultad, desde luego, no fue ejercida en esta causa. 
el Secretario de este Tribunal y que rola a fojas 120, no existe gestión pendiente donde pueda hacerse efectiva la declaración de inaplicabilidad por inconstitucionalidad que se solicita, lo que hace improcedente que esta Magistratura entre a considerar el fondo de las peticiones incluidas en el requerimiento; QUINTO: Que siendo suficiente la falta de gestión pendiente por no cumplir con uno de los presupuestos procesales básicos para que prospere la acción de inaplicabilidad por inconstitucionalidad. ${ }^{20}$

En suma, el Tribunal exige para el cumplimiento de este requisito, que la gestión exista no sólo al presentarse la acción, sino también que perdure hasta el momento de estudiarse su admisibilidad y, todavía más, hasta la fecha en que se dicte resolución de fondo del asunto requerido. ${ }^{21}$ Esta alta exigencia ha motivado que algunos autores critiquen el alto estándar adoptado por el Tribunal en materia de gestión pendiente. Buchheiser y Candia critican que la Constitución exige como requisito tan sólo la existencia de una gestión pendiente, sin señalar hasta cuándo ella deba existir. Por tanto, el precepto debe ser integrado a partir de los principios y valores constitucionales. La filosofía inspiradora de la reforma constitucional 2005, en ese sentido, fue potenciar las instancias de control constitucional. No se podría por vía formal, entonces, cerrar las puertas del Tribunal Constitucional. Es necesario interpretar estos requisitos constitucionales de forma amplia, potenciando su carácter garantista. De lo contrario, podrían seguir dándose los casos en que la sola demora del Tribunal en proveer un recurso presentado determinara la inadmisibilidad del mismo ${ }^{22}$.

La crítica parece válida. De hecho el mismo Tribunal ha afirmado que los requisitos de admisibilidad deben interpretarse en términos amplios. En efecto, en rol 972-07 desechó la interpretación restrictiva de la Dirección del Trabajo al estimar que acoger una interpretación tan restrictiva de los requisitos de admisibilidad de la acción de inaplicabilidad (...), significaría impedir que este Tribunal ejerza su deber de decidir el conflicto constitucional que, dentro de la esfera de su competencia, se le somete, el cual quedaría sin resolverse con el riesgo de que pueda darse una aplicación contraria a la Constitución a un precepto legal vigente, con el consiguiente quebranto del principio de supremacía constitucional (Rol 972-07).

Finalmente, el Tribunal ha entendido que existe gestión pendiente con la sola presentación de la demanda, aún cuando no haya sido notificada a la contraparte. Así lo resolvió en Rol 94607. Señaló que la gestión [que el requerido reclamada no existir aún] se encuentra actualmente pendiente ante ese tribunal pues, habiéndose presentado la demanda-acto de impulso procesal

\footnotetext{
$20 \quad$ Cfr. rol 524-06.

21 Cea, José Luis, «El Tribunal Constitucional y el control de las leyes », en Escritos de Justicia Constitucional, Santiago, Cuadernos del Tribunal Constitucional, $\mathrm{N}^{\circ} 35,2007$, p. 114: La condición analizada tiene que acreditarse al momento de ser ingresado el requerimiento a la secretaría del Tribunal Constitucional y mantenerse al pronunciarse la sala sobre su admisibilidad, una semana o varios días después de aquella recepción.

22 Buchheiser, Axel y Candia, Gonzalo, cit. nota 18, p. 204.
} 
La admisibilidad del recurso de inaplicabilidad: a tres años de la reforma.

que contiene generalmente el ejercicio de la acción y siempre la pretensión del actor (Juan Colombo, Los Actos Procesales, Ed. Jurídica, 1997, Tomo I, pág. 69)- mediante la presentación del reclamo ante el tribunal competente, éste no le ha puesto término por resolución con efecto de cosa juzgada, resultando indiferente para los efectos de la admisibilidad de la acción constitucional que la gestión se encuentre momentáneamente estática (cons. $12^{\circ}$ ).

ii) No existe gestión pendiente cuando se solicita la revocación o corrección de actos que se estiman ilegales o abusivos.

El Tribunal también ha declarado inadmisibles requerimientos fundados en actos eventualmente contrarios a la Constitución, que solicitan a la Magistratura dejarlos sin efecto.

El criterio se encuentra en rol 966-07. El requirente solicitó la inaplicabilidad de "actos reiterados y recientes", en contra del Instituto de Normalización Provisional de Chile, al considerar que ellos "violan la Carta Política del Estado". El Tribunal desechó la presentación al constatar que los actos impugnados ya se encontraban consumados, por lo que resultaba clara la ausencia de una gestión pendiente. Señaló, en la oportunidad, que el requerimiento se dirige en contra de "actos reiterados" del Instituto de Normalización Previsional, señalando que esa institución "ha rechazado todas mis presentaciones" y reiterando que "este acto y los otros tantos cometidos por el I.N.P." le causan agravio, a lo que se añade que la acción intentada sería la oportunidad "para corregir tamaños actos lesivos cometidos por el I.N.P.”, para finalmente solicitar que "sean dejados sus efectos de los actos cometidos", todo lo cual deja claramente establecido que el escrito no cumple con la exigencia constitucional de existir "una gestión pendiente ante el tribunal ordinario o especial”.

iii) La carga de probar la gestión pendiente corresponde al requirente.

Otra serie de roles han sido declarados inadmisible porque el requirente no ha acreditado la gestión pendiente en la que presuntamente se aplicará el precepto cuya constitucionalidad se impugna. La prueba de la gestión pendiente, de este modo, pasa a constituir una auténtica carga procesal para la admisibilidad del recurso. En efecto, el Tribunal se ha pronunciado en el sentido de que la carga de acreditar la existencia de una gestión pendiente incumbe al requirente [lo que no se ha cumplido en la especie] (Rol 550-06, cons. $\left.10^{\circ}\right)^{23}$.

iv) El precepto impugnado sólo debe incidir en una sola gestión pendiente.

23 Sin embargo, el Tribunal puede solicitar a su secretaría información de la gestión pendiente, en caso que el requirente no la identifique o no la haya acreditado debidamente. 
Por otro lado, se ha precisado este requisito señalando que el requerimiento debe aludir exclusivamente a una -y sólo a una- gestión pendiente donde podría incidir el precepto legal impugnado. En consecuencia, se han declarado inadmisibles las presentaciones que solicitan la inaplicabilidad de un precepto para dos o más causas o gestiones pendientes. La razón es que no resulta admisible que se formulen en un solo requerimiento de inaplicabilidad, impugnaciones respecto de un mismo precepto legal, pero que corresponden a dos gestiones judiciales pendientes de resolución, diversas e independientes (Rol 984-07 cons. $4^{\circ}$ y $\left.5^{\circ}\right)^{24}$.

El requirente de esta causa pretendía, mediante un solo requerimiento, que se dejara sin aplicación un mismo precepto para dos causas que se encontraban actualmente en fase de apelación. La respuesta negativa del Tribunal se fundó que la forma en que se ha presentado la acción, (...), es contraria al requisito de admisibilidad según el cual cada requerimiento debe estar referido, en concreto o en forma singular, a la "existencia de una gestión pendiente ante el tribunal ordinario o especial" en la que los preceptos impugnados puedan resultar derecho aplicable. Lo anterior se confirma por el hecho de que la decisión jurisdiccional que emita esta Magistratura en la materia de que se trata, ha de recaer en la conformidad o contrariedad con la Constitución que la aplicación del precepto impugnado pueda tener en cada caso sub lite.

En síntesis, el Tribunal ha sostenido que para la procedencia del recurso de inaplicabilidad, resulta indispensable que se deduzca con relación a un juicio o gestión en particular, en términos que no puede aceptarse la interposición de un mismo o único requerimiento para obtener la declaración de inaplicabilidad respecto de procesos diversos que se sustancian separadamente, y sobre los cuales tampoco es posible saber el estado actual de su tramitación (Rol 727-07, cons. $\left.9^{\circ}\right) .{ }^{25}$

v) La gestión pendiente es la controversia principal que motiva la impugnación del precepto cuya aplicación puede resultar inconstitucional.

El criterio fue adoptado en la causa rol 1064-08. En esa oportunidad un juez de garantía

Cfr. rol 1067-08, cons. $7^{\circ}$ : Que, asimismo, la declaración de inaplicabilidad se solicita respecto de dos procesos judiciales que se individualizan, lo cual, según ya ha declarado esta Sala del Tribunal, en los Roles $N^{\circ} 803-07$ y 832-07, "resulta contrario al requisito de admisibilidad según el cual el requerimiento debe estar referido, en concreto o en forma singular, a la "existencia de una gestión pendiente ante el tribunal ordinario o especial" en la que los preceptos impugnados puedan resultar derecho aplicable”.

25 Con todo, el Tribunal ha desechado presentaciones análogas a las indicadas en este punto, pero por carecer de fundamento razonable. Así, rol 727-07 cons. 9: Que de lo señalado precedentemente es posible concluir que, para la procedencia del recurso de inaplicabilidad, resulta indispensable que se deduzca con relación a un juicio o gestión en particular, en términos que no puede aceptarse la interposición de un mismo o único requerimiento para obtener la declaración de inaplicabilidad respecto de procesos diversos que se sustancian separadamente, y sobre los cuales tampoco es posible saber el estado actual de su tramitación. 
La admisibilidad del recurso de inaplicabilidad: a tres años de la reforma.

formuló un requerimiento para inaplicar el artículo 149 inciso 2 del Código Procesal Penal ${ }^{26}$, al estimar que por mera disposición de una autoridad administrativa (Ministerio Público) o legislativa, debe permanecer detenido el imputado, sin perjuicio que el órgano jurisdiccional competente (juez de garantía) haya estimado la no prolongación de la privación de libertad (...) por no cumplirse los requisitos indispensables que hacen procedente la prisión preventiva.

El Tribunal, lo declaró inadmisible al comprobar que la gestión en la cual incide el requerimiento (...) se encuentra concluida, toda vez que la Corte de Apelaciones de Santiago ya se ha pronunciado (...) por lo que los fundamentos para sostener la eventual aplicación inconstitucional de la norma impugnada pierden sustento, puesto que la resolución del tribunal a quo ha sido ya revisada por el tribunal superior jerárquico que la legislación señala poniendo fin a la gestión en que incidía el precepto cuestionado.

Sin embargo, el voto de disidencia ${ }^{27}$ discrepó de la interpretación que la mayoría hizo sobre la gestión pendiente:

Desde luego, se verifica la existencia de una gestión pendiente, que consiste en la investigación formalizada de un delito, lo que no parece dudoso en la especie. El precepto constitucional mencionado obliga también a esta Sala a verificar que "la aplicación del precepto legal impugnado pueda resultar decisivo en la resolución de un asunto ... " De las inequívocas expresiones de la Carta Fundamental, y particularmente de aquellas que han sido subrayadas resulta claro, a juicio de estos disidentes, que para declarar admisible un requerimiento basta con que el precepto pueda aplicarse y que tal aplicación posible pueda ser decisiva para resolver un asunto en la gestión pendiente. Así, la Constitución, en su afán por resguardar la primacía de la Carta Fundamental, no exige que el precepto sea apto para resolver la gestión pendiente, toda ella o siquiera sus aspectos medulares, sino que basta con la aptitud para resolver un asunto en la gestión pendiente. En la especie, y dado el carácter esencialmente revocable de las medidas cautelares, el inciso segundo del artículo 149 del Código Procesal

26 El precepto ha sido recientemente reformado por la "agenda corta antidelincuencia": Tratándose de los delitos establecidos en los artículos 141, 142, 361, 362, 365 bis, 390, 391, 433, 436 y 440 del Código Penal, y los de la ley $N^{\circ} 20.000$, que tengan pena de crimen, el imputado no podrá ser puesto en libertad mientras no se encuentre ejecutoriada la resolución que negare o revocare la prisión preventiva, salvo el caso en que el imputado no haya sido puesto a disposición del tribunal en calidad de detenido. El recurso de apelación contra esta resolución deberá interponerse en la misma audiencia, gozará de preferencia para su vista y fallo y será agregado extraordinariamente a la tabla el mismo día de su ingreso al tribunal de alzada, o a más tardar a la del día siguiente hábil. Cada Corte de Apelaciones deberá establecer una sala de turno que conozca estas apelaciones en días feriados.

27 Ministros Vodanivic Schnake y Correa Sutil. 
Penal puede seguir teniendo aplicación durante el transcurso del juicio o gestión pendiente a que está sometido el requirente. Conforme lo disponen los artículos 142, 144 y 145 del mismo Código, el precepto puede resultar decisivo en la resolución de un asunto (eventuales medidas cautelares futuras) que pueden decretarse durante el proceso, hasta tanto no se haya dictado la correspondiente sentencia definitiva o interlocutoria que ponga término al proceso y que se encuentre ejecutoriada.

La disidencia es relevante ya que permite determinar los alcances del voto de mayoría. Este circunscribe la gestión pendiente al específico asunto que puede ser resuelto mediante la aplicación del precepto que se impugna (la prisión preventiva que se apela) y no a la totalidad del conflicto jurídico de fondo. En este sentido, interpreta el alcance del tercer requisito de admisibilidad, limitando el asunto ("un asunto") en que puede resultar decisiva la aplicación del precepto legal (la investigación formalizada de un delito de la disidencia) a la gestión concreta en la que podría recaer dicho precepto (la apelación de la prisión preventiva no concedida por el juez de garantía). Es decir, para la mayoría del Tribunal el primer requisito de admisibilidad -la gestión pendiente- es, a la vez, "el" asunto al que se refiere el tercero de los requisitos $^{28}$.

Finalmente, la inaplicabilidad debe acotarse a los preceptos que pueden ser aplicados en la gestión que actualmente motiva el recurso. El requirente no puede solicitar la inaplicabilidad de un precepto ya aplicado en una gestión previa (una instancia pasada, por ejemplo) y, obteniendo una sentencia estimativa de inaplicabilidad, lograr que no se produzcan los efectos inconstitucionales que dicho precepto genera. El Tribunal así lo declaró al no admitir un requerimiento cuya gestión pendiente constituía la presentación de un recurso de queja por "la errónea calificación de los hechos" y "la privación ilegal del beneficio de remisión condicional de la pena". En la ocasión hizo presente que de declararse inaplicable el precepto legal debiera ser absuelta [la requirente] pues desaparece el tipo penal por el cual se le ha juzgado. Ello es efectivo, pero la gestión pendiente [la queja] ya no es el juicio de reproche penal, sino la eventual constatación de una falta o abuso en la dictación de una sentencia condenatoria, la que, naturalmente no puede consistir en haber dado aplicación al precepto legal impugnado que obliga al juez de la causa mientras no sea declarado inaplicable, lo que no ocurrió antes de la sentencia (Rol 1058-08, cons. $8^{\circ}$ ). 


\section{Falta de precepto legal}

\section{a) Observación previa:}

La ley es una norma general, altamente abstracta y permanente en el tiempo. El legislador no puede anticiparse a todos los casos y situaciones en que ella será aplicada. Su aplicación, en consecuencia, puede ser ajena a sus fines o contravenir principios y reglas de mayor jerarquía. Debido a que el juez tiene obligación de aplicar la ley, deberá interpretarla procurando que se ajuste a las normas de mayor jerarquía, especialmente la Constitución. Sin embargo, es perfectamente posible que el juez se encuentre frente a casos donde no resulte posible interpretar la ley según el principio de interpretación "conforme a la Constitución"29, por el cual -en palabras del mismo Tribunal- una norma será contraria a la Constitución sólo cuando no exista posibilidad alguna de comprenderla o darle eficacia dentro del marco de la misma (Rol $815-07$, cons. $\left.34^{\circ}\right)^{30}$. Y la única alternativa posible, para no dictar una resolución que infrinja las garantías constitucionales, será dejar de aplicar la ley en cuestión.

La acción de inaplicabilidad procede contra preceptos legales, precisamente, porque su generalidad puede llevar a que su aplicación a un caso particular genere efectos intolerables desde el punto de vista constitucional. A diferencia de los actos administrativos, nuestro ordenamiento no admite un sistema de control difuso de constitucionalidad de la ley ${ }^{31}$. La sentencia estimativa de inaplicabilidad es, por lo tanto, la única justificación legal que tiene el juez para eximirse legítimamente de la obligación general que sobre él pesa de aplicar la ley ${ }^{32}$.

\section{b) Jurisprudencia del Tribunal:}

El Tribunal ha señalado que el requerimiento debe individualizar con precisión el precepto legal cuya inconstitucionalidad se impugna. En virtud de lo anterior, ha declarado inadmisibles los escritos que solicitan un pronunciamiento sobre la inaplicabilidad por inconstitucionalidad de diversos textos legales señalados en forma indeterminada y genérica, sin precisar tampoco las normas constitucionales que se consideran vulneradas y la forma en que se produciría su

29 Para una explicación del concepto, cfr. García de Enterría, Eduardo, La Constitución como norma y el Tribunal Constitucional, Madrid, Civitas, 3ra edición, pp. 95-105.

30 Cfr. rol 681-06, cons. 24: Que las inconstitucionalidades constatadas precedentemente, ligadas, por lo demás, a principios cardinales del derecho público, ya precisados en esta sentencia, no admiten ninguna otra interpretación plausible que no conduzca necesariamente a la declaración de inconstitucionalidad del artículo 116 del Código Tributario.

$31 \quad$ Un completo estudio que critica la doctrina del control difuso en Chile en Letelier, Raúl, "Jueces ordinarios y justicia constitucional”, en Revista Chilena de Derecho, vol 34, N 3, pp. 539-574.

32 Cfr. Gómez, Gastón, "La reforma constitucional a la jurisdicción constitucional", en Reforma Constitucional, Santiago, Santiago, Lexis Nexis, p. 669. 
supuesta infracción. La falta de determinación impide al Tribunal identificar el conflicto constitucional preciso que debe resolver. Y por los mismo, se incumple con la necesidad de la suficiente determinación del o de los preceptos legales que se consideren violatorios de la Carta Fundamental (Rol 1048-08) $)^{33}$.

El Tribunal también ha desestimado una larga serie de requerimientos que solicitan la inaplicabilidad de actos administrativos. Como es lógico, el Tribunal se ha declarado incompetente y ha rechazado la admisibilidad de dichas acciones. La razón de fondo se puede apreciar en rol 706-07. Este tipo de asuntos [conflictos de constitucionalidad de actos administrativos] compete a los jueces de fondo resolver, competencia que este Tribunal debe respetar en virtud de lo dispuesto en el artículo $7^{\circ}$, incisos primero y segundo, de la Constitución, y en conformidad con el principio de deferencia razonada hacia los Poderes del Estado. No es, por lo tanto, un conflicto de aquellos comprendidos en el artículo 93, inciso primero, $N^{\circ} 6^{o}$, de la Carta Fundamenta. ${ }^{34}$

En continuidad con la jurisprudencia citada, el Tribunal ha señalado reiteradamente que no es una materia que corresponda plantear a través de una acción de inaplicabilidad, la oposición que una persona sostenga respecto de la interpretación que le ha dado un organismo de la Administración del Estado (...) a un determinado precepto legal aplicable al área de sus funciones. Esa clase de asuntos genera un conflicto de legalidad que no compete resolver a esta Magistratura Constitucional, sino que es propio de los jueces del fondo (rol 782-07, cons. $\left.7^{\circ}\right)$.

En otro orden de materias, tampoco se han admitido acciones dirigidas a impugnar resoluciones judiciales que a juicio del requirente vulneran derechos garantizados en la Constitución. La inaplicabilidad, este sentido, no sólo carece de gestión pendiente, sino también

$33 \quad$ Cfr. rol 550-06, cons. $9^{\circ}$ : Que en la especie se solicita al Tribunal Constitucional pronunciarse sobre la inaplicabilidad por inconstitucionalidad de diversos textos legales en forma indeterminada, sin establecer tampoco las normas constitucionales que considera vulneradas, y respecto de una gestión que no se ha acreditado. Por este mismo motivo, el Tribunal ha declarado inadmisible algunos requerimientos, pero por una causal distinta: falta de fundamento razonable, $C f r$. infra 4. ii.

$34 \quad C f r$. Rol 820-07, cons 6 ${ }^{\text {a }}$ : Que, en este caso, ello no ocurre, toda vez que lo que se solicita, según el tenor expreso del requerimiento de la especie, es la declaración de inaplicabilidad del artículo 44 de la Resolución $N^{\circ} 341$, de 2005, de la Dirección General de Aguas -que deja sin efecto la Resolución DGA No 186, de 1996, y establece nuevo texto de resolución que dispone normas de exploración y explotación de aguas subterráneas-, esto es, lo que se impugna es un acto administrativo y no un precepto le gal como lo exige el artículo 93, inciso primero, $N^{o}$ 6, e inciso undécimo de la Constitución, para deducir la acción de inaplicabilidad por inconstitucionalidad ante este Tribunal Constitucional.

La naturaleza de acto administrativo que reviste el texto normativo que contiene la disposición impugnada es reconocida por el propio requirente en la página 11 de su presentación, al señalar: "Conforme a lo anterior la Resolución $N^{\circ} 341$ de 2005 es, desde un punto de vista formal, un mero acto administrativo de Jefe de Servicio...”. 
La admisibilidad del recurso de inaplicabilidad: a tres años de la reforma.

de precepto legal específico para inaplicar, pues lo que se persigue es revisar sentencias judiciales ya dictadas. La acción de inaplicabilidad -ha sentenciado el Tribunal-es un medio inidóneo para impugnar resoluciones de órganos jurisdiccionales, ya que la salvaguarda del imperio de la ley en el conocimiento, resolución y ejecución de lo juzgado en causas civiles y criminales corresponde exclusivamente a los tribunales establecidos por la ley, a través de los medios procesales que el legislador establezca mediante los Códigos de Enjuiciamiento (Rol 794-07, cons. $\left.7^{\circ}\right)^{35}$

Similar criterio fue seguido en rol 551-06. Allí precisó que no le correspondía dejar sin efecto una decisión judicial a la que se le atribuye haber dejado de aplicar el derecho vigente de Chile (...), pues tal asunto tiene naturaleza de infracción de ley que típicamente corresponde resolver a la Corte Suprema de Justicia (ibid.). ${ }^{36}$ Algunos autores, sin embargo, han hecho presente que la inaplicabilidad podría ser utilizada para casar sentencias, y el Tribunal terminar convertido en una Corte de "supercasación", al tener la última palabra sobre cómo deben interpretarse las leyes según la Constitución ${ }^{37}$. Y esto, desde luego, por sobre las resoluciones de las magistraturas de fondo. En este sentido, el Tribunal Constitucional sí tendría facultades para revisar fallos y dejarlos sin validez.

El Tribunal, por otra parte, se ha declarado incompetente para determinar cuál es la interpretación legal que debe preferirse para resolver un conflicto. Por lo mismo, ha dejado en manos de los jueces de fondo esta labor, restringiendo su competencia a la sola declaración de inaplicabilidad cuando los efectos que genera un precepto vulneran lo dispuesto por la Constitución. La razón que ha manifestado para seguir este criterio dice relación con que la inaplicabilidad no es vía idónea para declarar que un Tribunal ha actuado ilegalmente, aunque se alegue que, con ese actuar ilegal, se haya excedido la competencia y con ello afectado la Carta Fundamental; pues la acción constitucional referida sólo está llamada a pronunciarse en caso que la afectación de la Constitución Política se produzca en razón de la aplicación de lo dispuesto en un precepto legal (Rol 1008-08, cons. $\left.8^{\circ}\right)^{38}$

35 Cfr. roles 497-06, 817-07, 841-07 y 586-06, cons. $4^{\circ}:$ (...) la parte requirente imputa precisamente a la Corte de Apelaciones extralimitarse en sus facultades. Al efecto, argumenta que: "La Ilustrísima Corte de Apelaciones al darle validez en nuestro derecho interno a un tratado internacional no vigente en Chile, no ha actuado conforme al debido proceso de Derecho, ha sobrepasado sus facultades Constitucionales”. Esta línea argumental también priva de competencia a este Tribunal, llamado a pronunciarse acerca de la inaplicabilidad de preceptos legales que puedan resultar contrarios a la Constitución y no a controlar la constitucionalidad de sentencias judiciales.

$36 \quad$ Un criterio similar en rol 586-06.

37 Cfr. Vega, Francisco; Zúñiga, Francisco, "El nuevo recurso de inaplicabilidad por inconstitucionalidad ante el Tribunal Constitucional. Teoría y práctica", en Estudios Constitucionales, año 4, n² 2, 2006, p. 155. El efecto de una declaración de inaplicabilidad, según los autores, es revocar la sentencia de la instancia precedente, si fue dictada aplicando el precepto impugnado. El juez debería, incluso de oficio, invalidar dicha sentencia. 
En una interesante sentencia el Tribunal desestimó una solicitud que, a propósito de la eventual aplicación de tratados internacionales no ratificados por Chile, perseguía una declaración sobre el derecho vigente en nuestro país. El Tribunal se declaró incompetente para ello, indicando que no le corresponde (...) rectificar actuaciones judiciales o dirimir acerca de la vigencia en Chile de determinadas normas, sino declarar inaplicables preceptos legales cuya aplicación pueda resultar contraria a la Constitución, conforme lo dispone el numeral 6 del artículo 93, lo que no se ha solicitado por la requirente (Rol 551-06)

Por otro lado, el Tribunal ha señalado que la expresión "precepto legal" no limita la posibilidad de solicitar la inaplicabilidad de una parte de un enunciado normativo. El Tribunal estima que es efectivo que un precepto legal puede ser sólo una parte del enunciado normativo que compone un mismo artículo o inciso de una ley y es perfectamente posible que el "precepto" que resulta contrario a la Constitución sea una parte de un artículo o sólo una parte de un inciso. Lo que importa, en el caso de las normas prescriptivas ${ }^{39}$, es que esa parte o porción del inciso constituya un precepto, en el sentido de ser una unidad lingüística que establezca las conductas que hacen debida la consecuencia, los sujetos obligados y las consecuencias mismas. Así, es posible que se solicite la inaplicabilidad de fragmentos de un artículo o componentes de enunciados normativos, siempre que cumplan con los requisitos indicados. En definitiva, en opinión del Tribunal, para que una unidad lingüística (...) pueda ser considerada una norma o precepto legal de aquellos que trata el artículo 93 de la Carta Fundamental, no es necesario que sea completa; esto es que constituya una unidad autárquica capaz de producir efectos jurídicos al margen de otras normas. En efecto, [s]uponer que un "precepto legal" está constituido por la unidad de todas las normas que se vinculan unas a otras resultaría en un efecto absurdo para la institución de la inaplicabilidad, pues en tal procedimiento, el Tribunal Constitucional no podría declara inaplicable una disposición jurídica sin hacerlo con todas las normas asociadas a ella, aunque no fueran ellas las responsables de producir un efecto contrario a la Constitución (Rol 626-06). ${ }^{40}$

Guiado por el criterio recién descrito el Tribunal ha justificado la inaplicabilidad de preceptos legales que constituyen sólo una parte de un artículo, cuando [d]eclarar inaplicable todo el artículo implicaría entonces mantener y acrecentar el efecto contrario a la Constitución que el mecanismo de la inaplicabilidad ha procurado evitar (Rol 944-07, cons. $\left.18^{\circ}\right)$.

39 El Tribunal define este tipo de normas como aquellas que atribuyen un derecho a favor de quien cumpla con determinados requisitos; esto es, una disposición según la cual, en caso de poder verificar un sujeto una conducta, surge un deber: el del juez de considerarle como titular de un derecho (cons. $5^{\circ}$ ).

$40 \quad$ El mismo criterio ha orientado las sentencias de rol 747 que declaró inaplicables las frases "procediendo de plano" y "en cuenta, salvo que estime conveniente" de los artículos 539 y 551 del COT, respectivamente; y de rol 755 donde la expresión "gratuitamente" del artículo 545 (abogado de turno) del COT fue dejada sin aplicación. 
La admisibilidad del recurso de inaplicabilidad: a tres años de la reforma.

Con todo, el Tribunal ha señalado también que escapa a su competencia modificar mediante su interpretación el contenido de un precepto, asunto que corresponde exclusivamente al legislador. Lo que el requerimiento de rol 626-06 perseguía -así razonó éste- es una tarea distinta a la de inaplicar preceptos (que cierta doctrina suele denominar de legislador negativo). El intentado es un requerimiento para modificar la ley, en un sentido que, aunque pudiera considerarse más acorde con la Constitución, esta Magistratura no puede acometer sin exorbitar la competencia que la Constitución le asigna (626-06.) ${ }^{41}$.

Finalmente, el mayor número de sentencias de inadmisiblidad han sido las dictadas con posterioridad a la declaración de inconstitucionalidad del artículo 116 del Código Tributario ${ }^{42}$. Como se sabe, la sentencia rol 681 de marzo de 2007 derogó el artículo en cuestión, luego de una extensa serie de inadmisibilidades declaradas tanto por el Tribunal como, en su momento, por la Corte Suprema, quienes estimaron contrario al debido proceso la delegación de jurisdicción del Director Regional del Servicio de Impuestos Internos en algún funcionario del Servicio, para actuar como juez tributario ante las reclamaciones presentadas por los contribuyentes.

El problema que a partir de entonces se generó dice relación con los alcances del artículo 94 de la Constitución, que limita expresamente los efectos de la sentencia de inconstitucionalidad: ella no producirá efecto retroactivo (inciso 3). En otras palabras, las situaciones jurídicas configuradas bajo la vigencia del precepto mencionado conservan todos sus efectos, no así las futuras, respecto de las cuales dicha norma ya no puede tener aplicación, pues no sigue vigente. El Tribunal, en atención a este efecto, no ha entrado a pronunciarse sobre las acciones de inaplicabilidad presentadas con posterioridad a la derogación del precepto, a pesar que este se haya aplicado y haya producido a la fecha todos sus efectos.

El Tribunal, en otras palabras, ha manifestado su imposibilidad para declarar inaplicable un precepto que, a la fecha del requerimiento, ya no forma parte del ordenamiento legal aplicable:

41 Con todo, esta declaración resulta contradictoria con el criterio utilizado por el Tribunal para acoger la inaplicabilidad de rol 944-07. Allí declaró inaplicable sólo una parte del precepto impugnado, no obstante estar conciente de que con ello se estaba alterando el sentido del precepto. El considerando $18^{\mathrm{a}}$ de la sentencia señala: Que debe aceptarse que la inaplicabilidad de la condición referida en el considerando anterior altera el sentido de lo preceptuado en la Ley $N^{o} 18.900$ y en su artículo $5^{\circ}$ en particular. La intención del legislador fue efectivamente condicionar el traspaso de las deudas a un acto normativo posterior y, en el caso del juicio sub lite, podría verse obligado a asumirlas incondicionalmente. Así se justifica que ocurra por varios motivos [expone cuatro razones para justificar que la inaplicabilidad puede alterar en el caso sub lite el sentido de la norma].

42 Por causa del gran número de "autos motivados" presentados por la Corte Suprema y algunas Cortes de Apelaciones, el Tribunal ha dejado de resolver las presentaciones en sala y lo ha hecho en pleno (cfr.www.tribunalconstitucional.cl, sentencias del 22 de julio de 2008, [visitado el 13.03.2009]), queriendo mostrar, en nuestra opinión, el acuerdo general que existe en el Tribunal sobre este punto. 
el conflicto de constitucionalidad planteado por el requirente ha dejado de existir, toda vez. que, revocada la delegación de facultades del artículo 116 del Código Tributario, dicho precepto no puede recibir aplicación, más aún si se encuentra derogado, por lo cual resulta improcedente que esta Magistratura se pronuncie acerca de la inaplicabilidad por inconstitucionalidad del mismo (Rol 631, cons. $7^{\circ}$ ).

\section{Que el precepto legal pueda ser decisivo para la resolución de un asunto}

\section{a) Observación previa:}

Un precepto es decisivo cuando su aplicación determina la forma como se resolverá un asunto. No es decisivo porque resuelve el asunto -el requisito no está formulado en esos términos-, es decisivo porque el asunto se resuelve de una determinada manera: contraria a la Constitución. Esto explica que el Tribunal haya desechado sistemáticamente las alegaciones que sostienen que los preceptos meramente adjetivos o procesales no resultan decisivos para resolver el conflicto de fondo. Así lo ha declarado respecto del llamado solve et repete, condición para ciertas impugnaciones administrativas, ${ }^{43}$ como también del artículo 116 del Código Tributario, hoy sin vigencia ${ }^{44}$, sin perjuicio de que ambas sean normas ordenatorias de la litis. Estas, aunque no resuelven el conflicto (no son norma decisoria litis), son decisivas para que el conflicto se resuelva, a juicio del Tribunal, de un modo contrario al debido proceso judicial.

El Tribunal, por otra parte, debe ser cuidadoso en el análisis de este requisito, pues fácilmente puede incurrir en pronunciamientos sobre el mérito de la causa. La sentencia de inadmisibilidad que declara la impertinencia de un precepto para resolver un asunto, no debe, en consecuencia, impedir al juez de fondo aplicarlo: la prohibición únicamente le afecta cuando ha sido declarado inaplicable por sentencia de fondo del Tribunal. Un precepto "no decisivo" para el Tribunal, sí puede serlo para el juez y podrá aplicarlo a pesar de que el Tribunal no lo considere decisivo para resolver "un asunto" o la gestión pendiente.

43 Cfr. roles 546-06, 792-07, 946-07 y 968-07 (estas últimas sobre el mismo precepto: inciso 3 del artículo 474 del Código del Trabajo). Así, en 792-07: Tan decisivo en la resolución de un asunto-desde el punto de vista de la preeminencia de los derechos constitucionales- resulta el precepto cuya aplicación puede resolver el fondo del asunto, como el que permite, impide o dificulta ostensiblemente el conocimiento y decisión de la controversia. En cambio, la disidencia (Fernández Fredes y Urbina Zúñiga) estima que el precepto no puede tener aplicación decisiva en la resolución del asunto, pues es claramente un norma ordenatoria litis y por tanto, no puede tener incidencia alguna en la dilucidación del asunto que deberá fallar el aludido tribunal ordinario (cons. $1^{\circ}$ ).

$44 \quad$ Un ejemplo, entre muchos, es rol 472-06: la Carta Fundamental no ha establecido diferencias en relación con el tipo o naturaleza del precepto legal cuya inaplicabilidad se solicita, sino que ha aludido genéricamente a las normas con rango o valor de ley exigiendo solamente que "pueda resultar decisiva en la resolución del asunto". 


\section{b) Jurisprudencia del Tribunal:}

El Tribunal ha interpretado este requisito en términos amplios. El precepto cuya aplicación se impugna no debe, necesariamente, ser considerado por el juez de fondo para resolver el asunto. Basta la sola posibilidad de su aplicación para que pueda ser declarado inaplicable. La doctrina fue ampliamente desarrollada en rol 634-06, capítulo II. La parte requerida (Dirección Nacional de Aduanas) alegó que el precepto impugnado (artículo 13 de la LOC de Bases Generales de la Administración) no resultaba decisivo para la resolución del conflicto, puesto que si el precepto legal impugnado fuera declarado inaplicable (...) no tendría mayor efecto, pues no puede dejar de considerarse que existen otras normas jurídicas aplicables al caso sublite, que no han sido impugnadas en el presente requerimiento, que justificarían lo actuado por ese Servicio. El Tribunal desechó la cuestión preliminar, sentando, desde entonces, lo que será su doctrina en este punto. Argumentó que la necesidad de velar por el pleno respeto del principio de supremacía constitucional que persigue la declaración de inaplicabilidad de un precepto legal determinado en cualquier gestión que se siga ante un tribunal ordinario o especial, obliga a esta Magistratura a examinar si el precepto legal que se encuentra vigente y que se ha impugnado a través de la acción deducida, podría resultar contrario a la Carta Fundamental en su aplicación al caso concreto examinado. Para realizar el referido juicio de constitucionalidad basta que el juez que conoce de la gestión pendiente tenga la posibilidad de aplicar dicho precepto en la decisión que ha de adoptar y que, al hacerlo, pueda vulnerarse la Constitución, independientemente de que existan otros preceptos legales que también pueda considerar, los que deben estar asimismo indiscutiblemente subordinados a la Ley Fundamental (cons. 8) $)^{45}$.

La sola posibilidad de que el precepto impugnado sea aplicado, junto con su actual vigencia, es suficiente para que pueda ser examinado (por este Tribunal) a través de una acción de inaplicabilidad. El criterio del Tribunal, acertadamente amplía la causal de admisibilidad al incorporar un juicio de previsibilidad razonable de que el precepto legal pueda llegar a ser aplicado: es suficiente la posibilidad y no certeza plena de que el precepto legal impugnado sea aplicable en la gestión judicial (rol 808-07, cons. $7^{\circ}$ ).

Con todo, cabe la posibilidad de que normas no impugnadas puedan resolver el asunto en el mismo sentido que las declaradas inaplicables. Es decir, que el efecto negativo de la sentencia de inaplicabilidad sólo inhiba al juez respecto de las normas mencionadas en la parte resolutiva de la sentencia, pero no respecto de otros preceptos que le permitirían resolver en idénticos términos a como lo habría hecho de no haberse estimado la inaplicabilidad. Como se verá, tales preceptos no podrán ser aplicados por el juez, quien deberá sujetarse no sólo a lo 
estrictamente resuelto en el fallo de inaplicabilidad, sino también a su ratio decidendi. Por que, en definitiva, el objeto último de la acción de inaplicabilidad es que la resolución final del tribunal no sea, bajo ningún supuesto, contraria a la Constitución.

En la misma dirección, la Magistratura Constitucional ha insistido en que, (...) para fundar una acción de inaplicabilidad por inconstitucionalidad, es suficiente que la aplicación del precepto legal impugnado pueda resultar decisivo en la resolución de un asunto, correspondiendo al Tribunal únicamente verificar la posibilidad de que el precepto legal sea aplicado a un caso, para quedar obligada a pronunciarse sobre la acción deducida, y que la acción de inaplicabilidad es un medio de accionar en contra de la aplicación de normas legales determinadas contenidas en una gestión judicial y que puedan resultar derecho aplicable (Rol 943-07, cons. 9; énfasis en original). En la misma resolución el Tribunal respondió a la parte requerida, que aunque no se haya citado el precepto legal impugnado entre los fundamentos del petitorio de la demanda y de la contestación del juicio principal, pero luego se haya hecho presente en el requerimiento respectivo, el Tribunal se encuentre igualmente habilitado para emitir pronunciamiento sobre este, pues, como ya se ha visto, la sola posibilidad de su aplicación basta para que sea declarado admisible ${ }^{46}$.

Pese a lo anterior, la norma, en caso de ser aplicable debe influir en la decisión sustantiva del asunto. El Tribunal, por lo mismo, puede declara inadmisibles presentaciones que persigan dejar sin aplicación preceptos irrelevantes para la resolución del caso concreto. El argumento fue invocado en rol 1053-08: Que la simple lectura de dicha norma permite constatar que su aplicación no tendría el efecto de influir en la decisión sustantiva del asunto judicial concreto invocado que se encuentra pendiente (cons. $7^{\circ}$ ).

El Tribunal ha definido que no obstante un requerimiento haya aprobado el trámite de admisibilidad, este requisito puede ser vuelto a estudiar al momento de resolver el conflicto de constitucionalidad propiamente tal. ${ }^{47}$ Para ello, bastaría con que se advirtiera que efectivamente dicho precepto no resuelve o no es decisivo para la resolución del asunto sometido al conocimiento del Tribunal para no examinar el fondo del requerimiento deducido (cfr. Rol 634-06). Pues, el hecho que una de la Salas se haya pronunciado acerca de la admisibilidad, no

46 Sin embargo, el ministro Navarro Beltrán, en la prevención al voto de rechazo de rol 546-06, afirma una tesis contraria. El ministro considera que el precepto legal que se impugna por la requirente de inaplicabilidad debe ser considerado en el razonamiento que pronuncie el sentenciador o servirle de fundamento, (nada de lo cual se produce en la especie), y después de citar alguna doctrina nacional, concluye: el precepto legal debe ser considerado por el juez al momento de resolver el asunto, ya sea que diga relación con aspectos de carácter procedimental o de fondo [énfasis añadido]. En suma, a juicio de Navarro el juez de fondo debe necesariamente considerar el precepto, lo que termina por recluir la acción de inaplicabilidad a la segunda instancia, ya que antes no será posible saber si considerará el precepto en cuestión en su sentencia. 
La admisibilidad del recurso de inaplicabilidad: a tres años de la reforma.

exime al Tribunal de pronunciarse en la sentencia sobre la totalidad de las pretensiones planteadas por las partes en el proceso ${ }^{48}$, (incluidas, en este caso, aquellas pretensiones que el Director Regional del Trabajo presenta como causales de improcedencia de la acción) (Rol 946-07, cons. $7^{\circ}$ ).

Sin embargo, la última doctrina de la Magistratura parece haber cambiado. En rol 808-07 (12 de agosto de 2008) rechazó la alegación del requerido de no ser determinante el precepto para el resultado de la gestión, al estimar que la declaración de admisibilidad es de competencia exclusiva de la sala y no del pleno. Este carecería de atribuciones para juzgar lo resuelto por la respectiva sala: no es de competencia del Pleno revisar una declaración que es de exclusiva incumbencia de la Sala que la pronunció (cons. $7^{\circ}$ ). La nueva jurisprudencia se pone en línea con la posición del ministro Cea, para quien la admisibilidad está reservada a una sala del Tribunal, impide a este último intervenir para cualquier efecto y no es una determinación susceptible de ser revocada para dictar a continuación una resolución en sentido diverso, al producir cosa juzgada ${ }^{49}$.

El Tribunal, al igual que la jurisprudencia tardía de la Corte Suprema, ha desechado las impugnaciones usualmente esgrimidas por la parte requerida, de que los preceptos meramente procesales no cumplirían con este requisito de admisibilidad. El Tribunal ha desechado estos argumentos señalando que excluir normas procesales del ámbito de esta acción constitucional, es una extrapolación errada de conceptos propios del recurso de casación en el fondo -distinción entre preceptos ordenatorios y decisorios para la litis-, teniendo en cuenta que la supremacía de la Constitución es un valor cuya vigencia no puede ser condicionada por la fisonomía de disposiciones de rango inferior. Tan decisivo en la resolución de un asunto-desde el punto de vista de la preeminencia de los derechos constitucionales- resulta el precepto cuya aplicación puede resolver el fondo del asunto, como el que permite, impide o dificulta ostensiblemente el conocimiento y decisión de la controversia ( $\left.\mathrm{Rol} \mathrm{N}^{\mathrm{0}} 792\right)$.

Por otro lado, el Tribunal ha señalado que [l]a exigencia contenida en el artículo 93, inciso undécimo, en orden a que "la aplicación del precepto legal impugnado pueda resultar decisivo en la resolución de un asunto", no puede, (...), interpretarse prescindiendo de la finalidad que anima a la institución de la inaplicabilidad por inconstitucionalidad de la ley. Dicha finalidad -el resguardo de la supremacía constitucional- ha sido consignada por el mismo Tribunal cuando afirma que la exigencia constitucional se completa si dicho precepto legal puede resultar decisivo en la resolución del asunto o gestión pendiente, lo que implica que la inaplicabilidad declarada deba ser considerada por el juez llamado a resolverla, tanto en lo

48 En este caso, la parte requerida planteó como razones para la improcedencia del requerimiento la falta de gestión pendiente y la falta de carácter decisivo en la resolución del asunto del precepto impugnado.

49 Cfr. Cea, José Luis, cit. nota 1, pp. 112-113. 
que se refiere a los fundamentos de ésta cuanto a todo otro razonamiento que implique que la decisión del asunto no resultará contraria a la Constitución (Rol 472-06, cons. 11²). La afirmación recién citada deja abiertas algunas preguntas. ¿Significa que el juez de fondo se encuentra habilitado para no aplicar otros preceptos -distintos del declarado inaplicable- de forma que la decisión no resulte contraria a la Constitución? ¿Es también vinculante la parte considerativa de la sentencia de inaplicabilidad? ¿Se rompe con esto el principio de la competencia específica, que el mismo Tribunal se ha autoimpuesto? Alguna doctrina ha interpretado, plausiblemente, la afirmación advirtiendo que "[n]o se trata (...) de extender la ratio decidendi más allá de la causa concretamente sentenciada (lo que no siempre será coherente con la íntima unión entre los hechos de la causa y la argumentación correspondiente), sino de aplicarla dentro de ella" ${ }^{50}$. En otras palabras, pareciera que el Tribunal estaría señalando que la sentencia de inaplicabilidad del precepto que resuelve el asunto, habilita al juez de fondo para ejercer un cierto control difuso de constitucionalidad sobre los preceptos conexos que pueden conducir a una resolución similar y por lo mismo, contraria a la Constitución ${ }^{51}$.

En otra sentencia, el Tribunal sentó una interesante doctrina sobre el requisito en estudio. En ella se admite que la invocación de un precepto legal en la parte petitoria de la demanda que da origen a la gestión pendiente configura una presunción a favor del carácter decisivo para la resolución del asunto. En síntesis, señaló el Tribunal:

OCTAVO: Que en el caso de autos y de la lectura de los antecedentes se desprende que el inciso $2^{\circ}$ del artículo 23 de la ley 19.542 puede resultar decisivo para la resolución de un asunto, en este caso el asunto de fondo controvertido, desde el momento que constituye una de las normas que invoca la requirente $n i$ más ni menos que para fundar la parte petitoria de su propia demanda. (...). Si bien el sentenciador de primera instancia no aplicó el precepto legal en cuestión desde el momento que acogió una de las excepciones opuestas por la demandada (...), no puede caber duda alguna que se trata de un precepto fundamental que sí puede ser considerado por la Corte de Apelaciones al momento de decidir la litis, tal como, por lo demás, lo señala la misma según consta en certificado que rola a fojas 43 ;

$50 \quad$ Núñez, Manuel A., "El control de la igualdad en la aplicación de la ley como factor de expansión del control concreto de constitucionalidad de las leyes", en Sentencias Destacadas 2007, Instituto Libertad y Desarrollo, Santiago de Chile, 2008, p. 143.

51 Esta conclusión bien podría ser desautorizada por el Tribunal, cuando afirma que posee la del control concreto de constitucionalidad de las leyes: el Tribunal Constitucional es el único órgano dotado de competencia privativa para pronunciarse sobre la inaplicabilidad de la ley vigente en un sistema concentrado de control (entre otras, rol $964-07$, cons. $1^{\circ}$ ). Con todo, el tenor literal del considerando analizado parece indicar lo contrario. Menos plausible, aunque no irrealizable, sería que el Tribunal indicara con esto que el juez debe plantear un nuevo requerimiento de inaplicabilidad al advertir los resultados a los que podrían estar conduciendo la aplicación de dichos preceptos. 
La admisibilidad del recurso de inaplicabilidad: a tres años de la reforma.

NOVENO: Que así las cosas, se desprende de autos la circunstancia que aun cuando el sentenciador de primera instancia rechazó la demanda de nulidad de derecho público, el artículo 23 inciso $2^{\circ}$ de la Ley 19.542 sí tiene el carácter de norma decisiva para la resolución de un asunto, por lo que se desestimará la petición formulada por la requerida en cuanto a que no se darían los presupuestos de admisibilidad de la acción de inaplicabilidad, en los términos que preceptúa el artículo $93 N^{\circ} 6$ de la Constitución Política de la República;

Sin perjuicio de lo anterior, el mismo Tribunal puede destruir esta presunción mediante un razonamiento lógico que descarte dicha posibilidad. Ello, sin embargo, deberá hacerse en la sentencia de fondo que rechace la inaplicabilidad y no en el estudio de admisibilidad del requerimiento. Así, por ejemplo, en rol 661-06 el Tribunal, en la sentencia de fondo, señaló que el artículo 416 inciso segundo del Código Procesal Penal, en caso de que se pretendiera aplicar al procedimiento con ocasión del cual se ha interpuesto la acción de inaplicabilidad, no produciría efecto alguno contrario a la Constitución. Ello, porque el mencionado precepto, lejos de producir una vulneración en los derechos, garantías o privilegios de los diputados o senadores, asegura el respeto del fuero de que gozan los parlamentarios. Una consideración de este tipo basta al Tribunal para formarse convicción de que lo anterior resulta evidente y suficiente para rechazar la acción impetrada (considerandos $8^{\circ}$ y $9^{\circ}$ ).

Se ha discutido, en otro orden de cosas, si el precepto debe ser decisivo para la resolución de un asunto cualquiera o bien, para resolver la gestión concreta que está conociendo el juez de fondo. La redacción de la Constitución parece dejar abierto este punto. En general, la jurisprudencia del Tribunal tiende a considerar "el asunto" como el conflicto que toca resolver y no uno indeterminado en el que podría llegar a ser relevante el precepto que se impugna. En rol 831-07 se aprecia claramente la equivalencia hecha por el Tribunal: Que del examen de los antecedentes que obran en autos resulta claro que las normas impugnadas no pueden tener incidencia decisiva para la resolución de la gestión pendiente invocada en el requerimiento (cons. $8^{\circ}$; énfasis añadido).

\section{Fundamento razonable de la inaplicabilidad}

\section{a) Observación previa:}

La especial dificultad que reviste el estudio de admisibilidad de esta causal consiste en deslindar lo que es estrictamente necesario para que se admita el requerimiento de aquello que será materia del pronunciamiento de fondo. En este punto es donde cobra especial relevancia el principio pro requirente, de modo que la causal se interprete en términos amplios, como de hecho ha sucedido. 
A pesar de lo anterior, se pueden encontrar inadmisibilidades declaradas con razonamientos propios de una sentencia de fondo y no de una interlocutoria de admisibilidad. Por ejemplo, en rol 996-07 la ministra Marisol Peña, en voto de minoría, estuvo por declarar admisible el requerimiento estimando que se cumplen los requisitos exigidos en el artículo 93, inciso undécimo, de la Carta Fundamental para estos efectos y que la consideración de si la norma contenida en el artículo 384 del Código del Trabajo cumple con el mandato conferido al legislador en el artículo 19, $N^{o} 16$, inciso sexto, de la Constitución, y de los efectos que ello produciría, es propia del pronunciamiento de fondo de la acción de inaplicabilidad deducida y no de su admisibilidad.52

Una alternativa para resolver esta dificultad consiste en interpretar la razonabilidad de la fundamentación como una exigencia que prima facie no es identificable en sede de admisibilidad, a menos que exista absoluta claridad acerca de la insuficiencia argumentativa del requerimiento. De no ser evidente la falta de fundamentos o si el requerimiento carece de algunas de las características mínimas que supone este requisito, ya discernibles en la jurisprudencia, el Tribunal debe acoger las presentaciones y postergar para la sentencia de fondo las consideraciones que le merecen los fundamentos de la acción, por débiles que sean.

\section{b) Jurisprudencia del Tribunal:}

i) El requerimiento debe indicar la forma precisa como la aplicación del precepto que se impugna contravienen la Constitución.

En reiteradas sentencias de inadmisibilidad el Tribunal ha señalado que el requerimiento debe expresar, al menos someramente, las razones que llevan a considerar la aplicación de un determinado precepto contrario a la Constitución. Por esta razón, hay incumplimiento del requisito cuando no se entregan fundamentos respecto de los efectos inconstitucionales que, eventualmente, provocaría la aplicación en el juicio pendiente de las normas legales que se impugnan, (...) (Rol 1036-07, cons. $\left.7^{\circ}\right)$.

52 El razonamiento de mayoría ciertamente fue propio de una sentencia de fondo, cuestión que se desprende con claridad del principal argumento expuesto y que por lo mismo conviene citar íntegro: De lo expuesto en el mismo requerimiento resulta claro, entonces, que el artículo 384 del Código del Trabajo ha sido dictado para dar cumplimiento al mandato del inciso final del $N^{\circ} 16$ del artículo 19 de la Constitución, por lo que resulta contradictorio que los ocurrentes soliciten que este Tribunal declare su inaplicabilidad por inconstitucionalidad basándose, precisamente, en que su aplicación al caso concreto vulnera la reserva legal prevista en la disposición constitucional que ordena su dictación, pues, de accederse a su pretensión, el resultado será la creación de un vacio legal que dejaría sin cumplirse un expreso mandato constitucional y, por consiguiente, en lugar de resolverse un conflicto de constitucionalidad se provocaría una situación de hecho contraria a la Constitución, lo que priva de su razonabilidad al fundamento del requerimiento de autos (cons. $5^{\circ}$ ). 
La admisibilidad del recurso de inaplicabilidad: a tres años de la reforma.

No es suficiente, por tanto, que el requerimiento exponga en abstracto la contradicción entre la norma legal y la constitucional. Debe especificarse siempre la forma como en la aplicación de la norma legal se genera un efecto contrario a la Constitución. En función de lo anterior declaró inadmisible el requerimiento de rol 492-06, al constatar que el análisis y desarrollo que se hace en la presentación acerca del modo en que los artículos 3 y $4, n^{\circ} 2$, de la Ley 17.235, vulneran el ordenamiento constitucional es manifiestamente insuficiente. Para sustentar lo dicho, aclaró que basta mencionar al respecto, por vía de demostración, la manera como se describe la infracción al principio de legalidad tributaria que se invoca. En lo esencial, únicamente se indica que aspectos fundamentales del tributo "quedan entregados a decisiones administrativas". Sin embargo, no se analiza cuales son esos aspectos y por qué se estima que son materia de reserva legal. Más aún, a fojas 3 se alude tan solo a uno de ellos, indicándose, expresamente, que se lo cita a modo de ejemplo ${ }^{53}$.

ii) El requerimiento debe referirse a normas legales precisas, no a un texto legal completo o a preceptos no individualizados.

En atención a que el efecto propio de la declaración de inaplicabilidad consiste en marginar ciertas normas legales para que el juez no las aplique en su resolución, el Tribunal ha desechado como inadmisibles acciones que no especifican los preceptos cuya aplicación se impugna. Así, ha dicho que no puede considerarse como razonablemente fundado el requerimiento, en primer lugar, porque se encuentra dirigido (...) contra un texto legal completo, y en subsidio, en contra de disposiciones citadas de manera genérica, a pesar de que se aluda en particular al artículo 138, todo lo cual, como lo ha expresado este Tribunal, "no es consistente con la filosofía de la acción de inaplicabilidad, la que supone individualización de preceptos legales concretos y determinados que en su aplicación produzcan efectos contrarios a la Carta Fundamental»; «no cabe la inaplicabilidad respecto de «impugnaciones genéricas y abstractas» (Sentencias Roles 495 y 523) (Rol 1036-08, cons. 5).

En otros términos, no se cumple con el requisito cuando se persigue un pronunciamiento del Tribunal sobre la inaplicabilidad por inconstitucionalidad de diversos textos legales señalados en forma indeterminada y genérica, sin precisar tampoco las normas constitucionales que se consideran vulneradas y la forma en que se produciría su supuesta infracción (Rol $1048-08$, cons. $\left.8^{\circ}\right)^{54}$

\footnotetext{
53 Por no hacer explícita la forma sobre cómo los preceptos impugnados contravenían en su aplicación la Carta Fundamental, fueron igualmente declarados inadmisibles los siguientes roles: $1049-08$ cons. $7^{\circ}, 1048$ cons. $8^{\circ}$, 1036-08 cons. $7^{\circ}, 1019-07$ cons. $8^{\circ}, 1004-07$ cons. $9^{\circ}, 708-07$.

54 Cfr. nota 25 .
} 
iii) Concordancia entre la parte expositiva y el petitorio de la acción de inaplicabilidad

El Tribunal, invariablemente, ha declarado inadmisibles los requerimientos en los que la parte expositiva del escrito no coincide o es contradictoria con su petitorio. Y así, por ejemplo, en Rol 492-06 declaró inadmisible la presentación al constatar que hay una evidente contradicción entre la parte petitoria del requerimiento y el cuerpo del mismo. En la primera, se solicita la declaración de inaplicabilidad de los artículos 3 y $4, n^{\circ} 2$, de la ley 17.235. No obstante, en el segundo, se indica que las disposiciones que se estiman inconstitucionales son los artículos $3,4, n^{\circ} 2$ y 1 de dicho cuerpo legal. ${ }^{55}$

iv) La norma legal impugnada no se encuentra vigente

Tampoco se cumple con el requisito en análisis cuando el requerimiento se basa en normas legales que han perdido vigencia o son invocadas sin atender a que han sido reformadas. Como se puede observar en rol 1021-07, el Tribunal constató: Que el mismo vicio de falta de fundamento razonable se observa respecto del requerimiento de la especie, pero esta vez, en cuanto se solicita la inaplicabilidad por inconstitucionalidad de una norma legal que no se encuentra vigente al tiempo de la interposición de dicha acción. En efecto, ello ocurre respecto de la impugnación que se dirige en contra del artículo $1^{\circ}, N^{o} 24$, de la Ley $N^{o} 19.585$, que incorporó al Título VIII del Libro I del Código Civil el artículo 199, cuyo inciso segundo, por orden del artículo $1^{o}, N^{o} 3$, de la Ley $N^{o} 20.030$ fue, posteriormente, sustituido por nuevos incisos (cons. $7^{\circ}$ ).

Similar constatación hizo el Tribunal en rol 492-06 donde el requirente invocó un precepto constitucional cuya numeración después de la reforma de 2005 cambió. En efecto, en la presentación se afirma que éste (principio de legalidad tributaria) se encuentra comprendido en el artículo 61 de la Constitución, disposición que, con anterioridad a la Ley de Reforma Constitucional $N^{\circ} 20.050$, de 26 de agosto de 2005, regulaba la institución de la delegación de facultades legislativas -actualmente lo hace el artículo 64- sin ni siquiera mencionar los preceptos de la Carta Fundamental que sustancialmente lo consagran (al principio de legalidad tributaria).

v) Forma de exponer la inconstitucionalidad de la aplicación del precepto.

No han sido pocos los fallos donde el Tribunal ha declarado que la exposición de la inconstitucionalidad de un precepto debe cumplir determinadas características. El requisito - a juicio de la Magistratura- supone que la presentación debe hacer explícita la aptitud del o de

$55 \quad C f r$. en este mismo sentido rol $1021-08$, cons. $5^{\circ}$ y $768-07$, cons. $6^{\circ}$ y $7^{\circ}$. 
La admisibilidad del recurso de inaplicabilidad: a tres años de la reforma.

los preceptos legales objetados para contrariar, en su aplicación al caso concreto, la Constitución, lo que debe ser expuesto circunstanciadamente, de modo que la explicación de la forma en que se produce la contradicción entre las normas, sustentada adecuada y lógicamente. Es esta aptitud aquello que, en palabras del Tribunal, constituye la base indispensable de la acción ejercitada (Rol 1055-08, cons. $\left.10^{\circ}\right)^{56}$.

La exposición circunstanciada se refiere a la mención de los efectos y del contexto de la aplicación de la norma legal, lo que tras la reforma de 2005 se torna indispensable dado el marcado carácter concreto que adquiere la inaplicabilidad. Sin embargo, la forma transcrita, que se ha vuelto habitual en muchas inadmisibilidades, incurre en el error de exigir una explicación sobre la forma lógica como el precepto impugnado contradice la Constitución (forma en que se produce la contradicción entre las normas). Esto podría significar, a nuestro juicio, un retorno al estado anterior, cuando el recurso llevaba a un ejercicio de examen norma (legal)/norma (constitucional) y no de aplicación de la norma legal en contraste a lo dispuesto por la norma constitucional, que es lo propio del control concreto.

En otras oportunidades la falta de fundamento razonable ha dicho relación con el sentido de los argumentos que fundan el requerimiento. Estos deben dirigirse a mostrar que el precepto aplicado al caso es inconstitucional. Deben, por tanto, indicar los hechos relevantes y la forma como se produce la contravención a la Constitución. Al contrario, las consideraciones abstractas dirigidas a demostrar a través de un juicio lógico la inconstitucionalidad de una norma han sido desechadas por el Tribunal como carentes de fundamento razonable. Basado en tal premisa el Tribunal estimó inadmisible la presentación de rol 1057-08, puesto que su fundamentación descansa más en razonamientos orientados a dar sustento en abstracto a pretensiones ajenas a la naturaleza de la acción deducida, que a demostrar por qué la aplicación en el caso concreto del precepto legal impugnado, resulta contraria a la Constitución (cons. $11^{\circ}$ ). Una consideración similar fue formulada para desechar el requerimiento de rol 967-07, pues a juicio de la Magistratura la argumentación que se desarrolla por la actora al formular el requerimiento dice relación básicamente con la contradicción genérica de las normas que impugna con la Constitución, lo que es propio de la declaración de inconstitucionalidad pero no de la acción de inaplicabilidad como actualmente se configura en la Carta Fundamental (cons. $\left.17^{\circ}\right)^{57}$. Finalmente, algo parecido sucedió en rol 616-06, porque a pesar de haber sido

$56 \quad C f r$. en el mismo sentido, roles $1067-08$ cons. $8^{\circ}, 733-07$ cons. $5^{\circ}, 782-07$ cons. $5^{\circ}$ y $492-06$ cons. $4^{\circ}$.

57 Sin perjuicio del criterio asumido por el Tribunal no deja de llamar la atención el número de declaraciones de inaplicabilidad en las que la Magistratura ha centrado su argumentación en razones de orden lógico y teórico con poca conexión al caso particular sometido a su conocimiento ( $c f r$ r rol 755-07 y 976-07). Una exposición de esta crítica en Bordalí S., Andrés, "Sentencia de inaplicabilidad por inconstitucionalidad del juez tributario", Revista de Derecho Universidad Austral, Vol. XIX, N² 2, 2006, p. 254. En otras, al contrario, llama la atención lo presente que tuvo el Tribunal las circunstancias del caso para resolverlo (rechazando el requerimiento), por ejemplo, rol 541-06, cons. $17^{\circ}$ o rol 546-06, cons. $11^{\circ}$ del voto por acoger el recurso. 
declarado preliminarmente admisible, el escrito fue luego desechado por idénticas razones a las ya expuestas: que los reproches de constitucionalidad van más bien dirigidos a los preceptos legales en abstracto y no al caso concreto, todo lo cual configura esta presentación como un recurso de inconstitucionalidad y no de inaplicabilidad (cons. $52^{\circ}$ ).

vi) Solicitudes propias de los jueces de fondo y pretensiones carentes de lógica

El Tribunal, atendiendo al principio de competencia específica ${ }^{58}$, ha dejado a los jueces de fondo la resolución de materias que son ajenas a la naturaleza y fines de la inaplicabilidad. En algunas ocasiones ha recurrido a la falta de fundamentos razonables para desestimar requerimientos cuya pretensión ha sido, por ejemplo, que se resuelva un problema de aplicación de ley en el tiempo. En rol 839-07 no se admitió una acción que solicitaba al Tribunal la inaplicabilidad de un precepto que podía llegar a ser aplicado, a pesar de haber sido dictado con posterioridad a los hechos supuestamente delictivos, pues a juicio del Tribunal, respecto de la exigencia señalada en la letra c) del considerando precedente ["que la impugnación esté fundada razonablemente"], no puede considerarse como razonablemente fundado un requerimiento de inaplicabilidad si, como en el deducido en estos autos, sólo se formula un cuestionamiento acerca de la aplicación de determinadas normas legales en el tiempo, lo cual compete resolver a los jueces del fondo y, por ende, no es de incumbencia de esta Magistratura Constitucional (cons. $6^{\circ}$ ).

Por otro lado, en rol 979-07 la acción fue declarada inadmisible, ya que el Tribunal estimó que no es fundamento razonable ni suficiente una ampliación de las normas legales que se invocan en un segundo juicio de inaplicabilidad, aunque se efectúe dentro de la misma causa principal. El razonamiento de la Magistratura fue el siguiente: no puede considerarse como razonablemente fundada la acción intentada en la especie, si resulta evidente que el conflicto de constitucionalidad que se plantea coincide con el que, en su oportunidad, ya fue resuelto por esta Magistratura al conocer del requerimiento de inaplicabilidad, Rol 468-2006, (...) en contra de la aplicación del artículo 299, $N^{o} 3$, del Código de Justicia Militar, en el proceso judicial en el que aquél fue condenado como autor del delito que esa norma establece, por sentencia dictada por el tribunal competente;

$6^{o}$. Que la circunstancia referida precedentemente no se altera por el hecho de que ahora se intente por el actor ampliar y complementar el cuestionamiento de fondo ya resuelto por este

$58 \quad C f r$ roles $815-07$, cons. $42^{\circ}$ y $623-06$. En esta última se cita la doctrina del ministro Colombo expuesta en $E l$ Debido Proceso Constitucional, Cuadernos del Tribunal Constitucional, Santiago, No 32, 2006, p. 68: "Se define como la facultad que tiene el tribunal para conocer de las materias que conforman un proceso determinado. Es la singularización al caso concreto. El tribunal asume competencia específica para conocer el proceso y resolver el conflicto que en él se ventila y de su ejercicio surgirá el efecto de cosa juzgada, y la ultra y extra petita cuando el tribunal la extralimite". 
La admisibilidad del recurso de inaplicabilidad: a tres años de la reforma.

Tribunal Constitucional, añadiendo al artículo 299, $N^{o} 3$, antes cuestionado, referencias a los artículos 431 y 433 del Código de Justicia Militar y aludiendo a lo sentenciado por esta Magistratura en el Rol 781, que recayó en un caso concreto diverso.

vii) Las causales del artículo 39 de la Ley Orgánica del Tribunal Constitucional

El Tribunal ha señalado que la Ley Orgánica Constitucional No 17.779, será aplicable en la tramitación de las inaplicabilidades mientras no exista una normativa orgánica que se ajuste a la reforma constitucional de 2005. En consecuencia, los requisitos de admisibilidad contenidos en el artículo 39 de dicha ley son también aplicables a los escritos de inadmisibilidad que se le presenten. Dichas exigencias se resumen en una exposición clara de los hechos y fundamentos de derecho del requerimiento y en la descripción precisa de la cuestión de constitucionalidad, señalando el vicio de inconstitucionalidad y las normas que se estiman transgredidas.

Si el requerimiento no cumple con los requisitos del artículo 39, comenzará a correr el plazo de 3 días indicado en el artículo 41 de la misma ley para subsanar los defectos o completar los antecedentes omitidos. En caso contrario, se tendrá por no presentado el requerimiento.

Con todo, en las declaraciones de inadmisibilidad de inaplicabilidades que no cumplen con los requisitos del artículo 39 no es fácil identificar un criterio claro. En un estudio sobre la primera jurisprudencia de inaplicabilidades del Tribunal, la ministra Marisol Peña individualizó algunos de estos criterios ${ }^{59}$. Sin embargo, una parte importante de esos criterios han sido asumidos en la jurisprudencia reciente por el requisito constitucional de admisibilidad de estar el requerimiento razonablemente fundado.

Por ejemplo, en roles 1190-08 y 1197-08, la primera sala del Tribunal declaró la inadmisibilidad, debido a que la impugnación deducida no se encontraba "razonablemente fundada", sin perjuicio que una minoría de ministro (Venegas y Fernández) estuvieron por aplicar lo preceptuado en el artículo 39 en relación al 41 de la Ley 17.779. Es decir, desecharon la posibilidad de que el requirente subsanara los defectos del requerimiento dentro de un plazo de 3 días e identificaron los requisitos del artículo 39 con la fundamentación razonable del escrito (93 inciso 11).

En este mismo sentido, en rol 1236-08 la misma sala declaró inadmisible una inaplicabilidad al estimar que el escrito que pretendía subsanar los defectos del requerimiento no cumplía con las exigencias constitucionales. Después de exponer las razones que justificaban la resolución 
concluyó la sala manifestando que, por consiguiente, la acción no contiene una impugnación razonablemente fundada ni tampoco cumple con los demás requisitos legales, en los términos que exige el inciso undécimo del artículo 93 de la Constitución ${ }^{60}$. Nuevamente, el fundamento razonable del escrito pareciera que asume los requisitos del artículo 39 de la ley orgánica.

\section{Conclusiones}

1. La jurisprudencia del Tribunal, transcurridos tres años desde la reforma de la ley 20.050, permite identificar los criterios que han orientado las declaraciones de inadmisibilidad. Sin embargo, creemos que todavía hace falta una mayor depuración de las razones que invoca. Muchos de los argumentos utilizados en sede de admisibilidad se pueden encontrar todavía en sentencias de fondo, generando entre los litigantes problemas de inseguridad sobre el alcance de los requisitos en estudio y, también, de desigualdad en el tratamiento de los requerimientos presentados.

2. Los requisitos de admisibilidad, tal como lo demuestran algunas de las resoluciones citadas, han sido interpretados en términos extensivos. El Tribunal, de esta forma, permanece fiel al principio pro control o pro requirente, que lo había caracterizado hasta ahora. Al margen de sus interpretaciones históricas, vemos que esta disposición abierta al control se ajusta al espíritu de la reforma constitucional de 2005, que reforzó sus atribuciones de control constitucional y extendió la legitimación para recurrir de inaplicabilidad.

3. La jurisprudencia de inadmisibilidades está marcada por consideraciones en torno a la naturaleza concreta de la acción de inaplicabilidad. El Tribunal, por tanto, ha declarado como carentes de fundamento razonable las presentaciones inspiradas en razonamientos propios de una acción de inconstitucionalidad que de inaplicabilidad para el caso concreto, donde el precepto podría ser aplicado.

4. El Tribunal ha descrito con relativa prolijidad los criterios rectores en materia de fundamentación razonable de las acciones de inaplicabilidad. Se diluye, en parte, el fundado temor de que se repita la experiencia de una interpretación inconveniente del requisito, como sucedió en épocas anteriores ${ }^{61}$.

5. En general, las salas del Tribunal no han diferido sustancialmente en la interpretación de los requisitos en estudio. La existencia de criterios similares entre las salas refuerza

\footnotetext{
60 Siguen esta misma doctrina las resoluciones de los roles $1263-08,1285-08$ y 824-07 cons. $5^{\circ}$ en relación a $13^{\circ}$.

61 Cfr. Fermandois, Arturo, Presentación de Sentencias Destacadas 2007, Instituto Libertad y Desarrollo, op. cit., p. 14.
} 
la seguridad de los litigantes, debiéndoles ser indiferente la asignación de sala que efectúe el presidente del Tribunal. La única divergencia de criterios se produjo cuando el Tribunal conoció en salas de las admisibilidades del artículo 116 del Código Tributario. Tanto las consideraciones del voto de mayoría como sus respectivos votos minoritarios se apoyan en razones distintas.

6. Mientras no se encuentre promulgada y publicada la reforma a la Ley Orgánica del Tribunal, no es posible asegurar que estos serán los criterios jurisprudenciales que guiarán al Tribunal en los próximos años. Pensamos, sin embargo, que el legislador orgánico debiera tomar en consideración la jurisprudencia acumulada para configurar los nuevos requisitos de admisibilidad que podría añadir a los ya individualizados en la Constitución. 
294 Revista IUs et PraXis - AÑo 15 - № 1 